\title{
Bridge Assessment, Management and Life Cycle Analysis
}

\author{
Antonio Saviotti ${ }^{1}$ \\ ${ }^{1} \mathrm{U}+\mathrm{P}$ Consulting Engineers, Brescia, Italy \\ Correspondence: U+P Consulting Engineers, Via Ferrini 30, Brescia, Italy. E-mail: lar_consulting@libero.it
}

Received: February 14, 2014

Accepted: March 17, $2014 \quad$ Online Published: April 30, 2014

doi:10.5539/mas.v8n3p167

URL: http://dx.doi.org/10.5539/mas.v8n3p167

\begin{abstract}
Existing bridges represents strategic components of infrastructural nets, actually matching with an increasing traffic flow. Despite their increasing age, and even if subjected to an increasing heavy traffic, these nets stands generally in a good structural health. At the same time, prolonged out of service due to structural problems are rare. Nevertheless, it is important to highlight the major causes of degradation reported in bridges, to achieve an adequate maintenance and design. In particular, the design stage should be aware that new structures should ensure growing capacity and structural performance along its lifetime. Bridge assessment help in this way: it is a relatively recent bridge engineering science growing faster, as the amount of resources needed for the complete repair of existing bridges is absolutely impossibile to be retrieved for the managing authorities. It is a scientific based and technical procedure, mainly not coded, aiming at producing evidences on the bridge health, of the structural reliability, and of the suggested procedure to prolong its life. The purpose of this study, is to provide a review of recent studies and research accomplishments in the field of bridge assessment, management and life cycle analysis.
\end{abstract}

Keywords: bridge, structural analysis, seismic assessment, fatigue and fracture, retrofit and rehabilitation

\section{Introduction}

The American Society of Civil Engineers (ASCE 2009) has recently highlited that more than $26 \%$ of the existing bridges in US are structurally deficient or is characterized by obsolescence in functionality. A total investment of one thousand billion dollars (ASCE 2009) has been estimated to be necessary only in the next five years to cover these deficiencies only in US. These costs, will certainly increase in the near future, and are mainly covered by public income, so there is a need to manage as well this problem, as at the same time the socio-economical growth of nations is strictly related with the functionality of its infrastructural system. Among infrastructural systems, transport infrastructures cover a large part of the lifeline system, able to connect cities, regions and nations. It is a preliminary need of every state to provide adequate infrastructures, reliable, functional, updated, safe. The approach to manage such an amount of bridges should be as much scientific as it is possible.

\section{Assessment Procedures of Existing Bridges}

The assessment of an existing bridge aims at producing evidence to demonstrate it will function safely over a specified residual service life, taking into account a specific code reference. It is mainly based on the results of assessing hazards and load effects to be anticipated in the future, and of assessing material properties, the geometry and the structural state of the bridge. Guidelines for assessment of existing structures have been developed in many countries; however, the occurrence of bridge assessment guidelines coming from codes or standards is rare. More frequently, such guidelines are prepared at a detailed level by scientific groups or research organisations. Whatever the source, the first issue deals with fixing risk acceptance criteria, which is quite difficult since it must be compatible to the code for new structures (limit state analysis, safety factor format, etc.). The second issue deals with the process of the assessment procedure, which is commonly separated in phases, starting from preliminary evaluation, through to detailed investigation, expert and finally advanced assessment, depending on the structural condition of the investigated structure (Pipinato, 2010a). A four phases assessment procedure is presented in the following (Pipinato, 2014).

\subsection{First Level: Preliminary Evaluation}

The preliminary evaluation is the first level of investigation aiming at removing existing doubts about the safety of existing structures, adopting fairly simple methods and identifying critical parts or members in the structure. In order to identify critical members, it is necessary to carry out an intensive study of the available original 
design documents, along with a visual inspection of the structure and a photographic survey. The inspection procedure is often coded by infrastructural agencies manuals and procedures; however, at least the following points must be checked:

- The bridge construction is conforming to the original drawings and/or differences between as-built and drawings.

- Bridge modification during service (rehabilitation, strengthening, changes in the static system, etc.).

- Presence of any visual evidence of degradation (damaged expansion joints, supports, corrosion, cracks, vibration or loose rivets, collision, lack of structural members etc.).

Moreover, if available, inspection and maintenance reports can be used, and reference should be made to the evaluation report. The preliminary evaluation should include codes and recommendations analysis procedure where available, and conservative assumptions where information is lacking or doubtful. In this way, critical construction details can be identified.

\subsection{Second Level: Detailed Investigation}

The aim of the detailed investigation is to update the information obtained in other analysis by carrying out a refined assessment, especially for those members for which adequate safety was not confirmed by preliminary evaluation. At this stage a specialised consultant should assist. In this phase a FEM numeric model of the entire structure is developed. Based on the current code provisions, the structure should be recalculated and verification tables should report whether the structural members are safe or not. Concerning specific issues, such as the fatigue and seismic behaviour of the bridge, detailed code provisions should be referred to. From this step-level investigation, non-destructive testing (NDT) could be used in order to characterise the basic material properties of the structure. The final report of the investigation should establish whether the structure is verified against specific issues and has sufficient static strength against actual loadings.

\subsection{Third Level: Expert Investigation}

In case of key structures that have major consequences in terms of risks or costs related to a decision, a team of experts is needed in order to carefully check the conclusions and proposals reached in the last phase. Discussions and further assessments using specific tools can also be carried out to help reach decisions. At this level, on-site testing could be adopted in order to provide the dynamic identification of the structure, as reported in the following example.

\subsection{Fourth Level: Advanced Testing}

This advanced level of investigation should be reserved for recurrent bridges along infrastructural nets, in which a rational procedure of analysis and intervention could help in determining if retrofitting interventions could be adopted, or if rational dismantling large scale operations are required. The procedure is based on a detailed survey of the existing bridge, a FEM analysis, a code verification procedure, NDT diffused sampling, and, based on these data on real scale testing of one case study structure, aims to determine the global static and cyclic behaviour of the bridge. In specific cases, on-site dynamic identification could be performed. Concerning the fatigue assessment, in this case a LEFM (linear elastic fracture mechanics) investigation is required. Concerning seismic analysis, non-linear analysis is required. Specific material testing analysis should be performed dealing with the case analysed. The advanced testing result should report on the various analysis performed, and should clearly state verification results indicating the specific retrofit needed for recurrent interventions. An advanced testing operation is reported in the following section, dealing with a recurrent existing bridge type in service along the railway lines.

\subsection{Literature Review on Bridge Assessment}

A wide amount on studies on the specific issue of bridge assessment could be found in literature, however, only some of these studies are strictly related to useful procedures aiming at producing evidences that a bridge should be retrofitted, as a result of a scientific and practical at the same time procedures. The general procedure is reported in a study dealing with the assessment of existing bridges, considering safety and security issues (Pipinato, 2011). Among specific studies, the applications of B-WIM (bridge-weight in motion) technology to bridge assessment (Znidaric, 2010) relates to a useful procedure of investigation using WIM approach; the use of B-WIM data for bridge assessment is described in Petschacher (2011); the bridge assessment and health monitoring with distributed long-gauge FBG sensors (fiber Bragg grating) and detailed investigations using HM (health managment) procedures could be found in Chunfeng et al. (2013); recommendations for dynamic allowance in bridge assessment are well described in O'Brien et al. (2010); concerning the FEM approach on the 
assessment of existing bridges, the role of finite element analysis in bridge assessment and design could be found in Cakebread (2010), and similarly, the benefits and use of FE modelling in bridge assessment and design could be found in Icke (2012); going on with the multiple reference impact testing for bridge assessment with drop hammer (Liao et al., 2013), which contains a more practical approcach to the assessment of existing bridges; the reliability-based bridge assessment using enhanced Monte Carlo to simulate extreme traffic loading by Enright et al. (2013) is more focused on theoretical applications, that are useful in case that the loads distribution in the past is not available or with difficult could be assessed; at the same level, concering SHM (structural health monitoring tecnicques), the deployment of a dense hybrid wireless sensing system for bridge assessment is accurately described in Gangone et al. (2011), and similarly the assessment of structural health condition through static and dynamic monitoring is reported in Sigurdardottir et al. (2011). Concerning the specific matter of metal bridges, the structural analysis and assessment tecniques of historical metal bridges has been described in Pipinato et al. (2010a); moreover, the residual service life of existing railway bridges and structural analysis and the fatigue reliability assessment of the Paderno bridge is highlighted respectively in Pipinato et al. (2010b) and Pipinato and Modena (2010); and an advanced application Is reported in Pipinato et al. (2012a). If a specific step level procedure for remaining fatigue life evaluation of one railway bridge is of interest, an introductive study is in Pipinato (2010a), while an application is reported in Pipinato (2010b). Finally it is of interest to cite methods for determining differences of attribute weight between evidences in bridge assessment, accounted for in Li et al. (2013), and similarly, an improved one-dimensional optimization algorithm in non-probabilistic reliability investigation and its application in bridge assessment is reported in Chen and Fan (2011).

\section{Bridge Managment}

Probably one of the most significant applications of contemporary BMSs (bridge management systems) could be found in the US. In 1991, the Intermodal Surface Transportation Efficiency Act (ISTEA) required all states to develop, establish and implement a BMS by October 1998. The ISTEA requirements, first distributed in 1991, stated that the BMS must be implemented on all state and local bridges. New Federal legislation, however, required implementation of BMS only for bridges on the National Highway System (NHS); therefore, use of BMS inspection for non-NHS bridges was optional (Sunley, 1995). The principle BMS used in the US is PONTIS (the acronym), developed in the early 1990s for the Federal Highway Administration (FHWA) and became an American Association of State Highway and Transportation Officials (AASHTO) product in 1994. It performs functions such as recording bridge inventory and inspection data, simulating condition and suggesting actions, developing preservation policy and developing an overall bridge program. The system allows representation of a bridge as a set of structural elements, with each element reported based on its condition. In 2002, 46 agencies throughout the nation had PONTIS licensing, and each State Highway Administration (SHA) could customize the system according to its needs (Robert et al., 2003). BRIDGIT was developed in 1985 by the National Cooperative Highway Research Program (NCHRP) and the National Engineering Technology Cooperation in an attempt to improve bridge management networks. This system has capabilities similar to the PONTIS system. There have been many research projects throughout the nation on which local agencies have worked with universities to develop their own BMS. Other BMSs developed by individual state agencies do have good specific functions and qualities, but they lack features that can satisfy all the demands of effective bridge management and maintenance procedures on a national scale. Other notable research and development efforts on BMSs took place in Iowa, Washington, Connecticut, Texas and South Carolina (Czepiel, 1995). Among recent European experience that we should remember is the TISBO (the acronym) Infrastructure Maintenance Management System, currently being developed by The Netherlands Ministry of Transportation, Public Works and Water Management. It is a system that integrates inspection registration and maintenance management. Concerning the Italian current situation regarding BMSs, owner agencies usually manage their network with self-developed codes/procedures. The policy of the main Italian agencies is briefly presented in the following: Rete Ferroviaria Italiana (RFI), is the National agency for the whole Italian railway network, consisting of about $16,000 \mathrm{~km}$. The BMS is based on periodical visual inspections supported by special testing trains. All data are elaborated with specific software developed by the agency with the aim of defining economical and technical convenience of possible maintenance/rehabilitation/ strengthening interventions. Autostrade per l'Italia is the most relevant highway agency in Italy and manages a network of about $3400 \mathrm{~km}$. The BMS is based on the SAMOA programme for surveillance, auscultation and maintenance of structures. ANAS (1997) is the Italian agency for roads having national interest and manages a network of about 26,700 km. The BMS is based on the 'National Road Inventory' and in-situ survey and is a web-based management application that is developed by the agency and updated regularly. Also in Japan a wide amount of experience could be cited in the framework of bridge management system, as in Yokohama et al. (2006), where the development of bridge management system for expressway bridges in Japan is described; or in Soma (2006) where the development and implementation of 
bridge management system in aomori prefectural government is delineated.

\subsection{Literature Review on Bridge Managment}

The specific matter of bridge management is not already deepen with a practical and useful way in the current literature. For this reason, in the following are reported some relevant studies related to the argument, that could help in understanding the basic and more scientifical advanced research on the matter. An introductive study on the bridge information modeling in sustainable bridge management could be found in Marzouk (2011); concerning the specific argument of railway, the network rail's bridge asset management could be found in Griffin and Patro (2013); while a more complicated approach is deepen in the description of deformation predication and management of large bridge based on radial basis function neural network by Linya et al. (2010). An accurate description of the the life-cycle information management practice of Shanghai Yangtze River Tunnel and Bridge Project is in Tian et al. (2012); while delaing with an approach considering bridge management and GIS instruments, the study dealing with management information system of road and bridge infrastructure based on ArcGIS engine (Xiaofang et al., 2012) is very interesting. A relative contemporary problem is faced in the study of the analysis and design of urban bridge safety early-warning management system by Rong et al. (2010) generally approaching the problematic of early warning systems, while a more focused article consider an integrated system for bridge management using probabilistic and mechanistic deterioration models, with specific application to bridge decks by Morcous et al. (2010); the scheduled maintenance and management actions, considering the residual life evaluation of railway infrastructures is described in Pipinato et al. (2008), while in Pellegrino et al. (2011b) a simplified management procedure for bridge network maintenance is deepen and applied; if a more deep approach on the risk modelling is requested, the advanced deterioration in bridge management systems by Thompson et al. (2013) should be of interest; while a very useful and interesting application of the integration of SHM into bridge management systems, with a case study, is presented in Figueiredo et al. (2011). As a fact, the economical aspects involving bridge management are increasingly important, so a stakeholder probability-based optimization approach for cost-effective bridge management under financial constraints by Orcesi and Frangopol (2011) should be a necessary lecture for these types of problems; and if a more complicated tools is desired, the multiobjective optimization for project selection in network-level bridge management incorporating decision-maker's preference using the concept of holism (Qiang et al., 2013) is very useful.

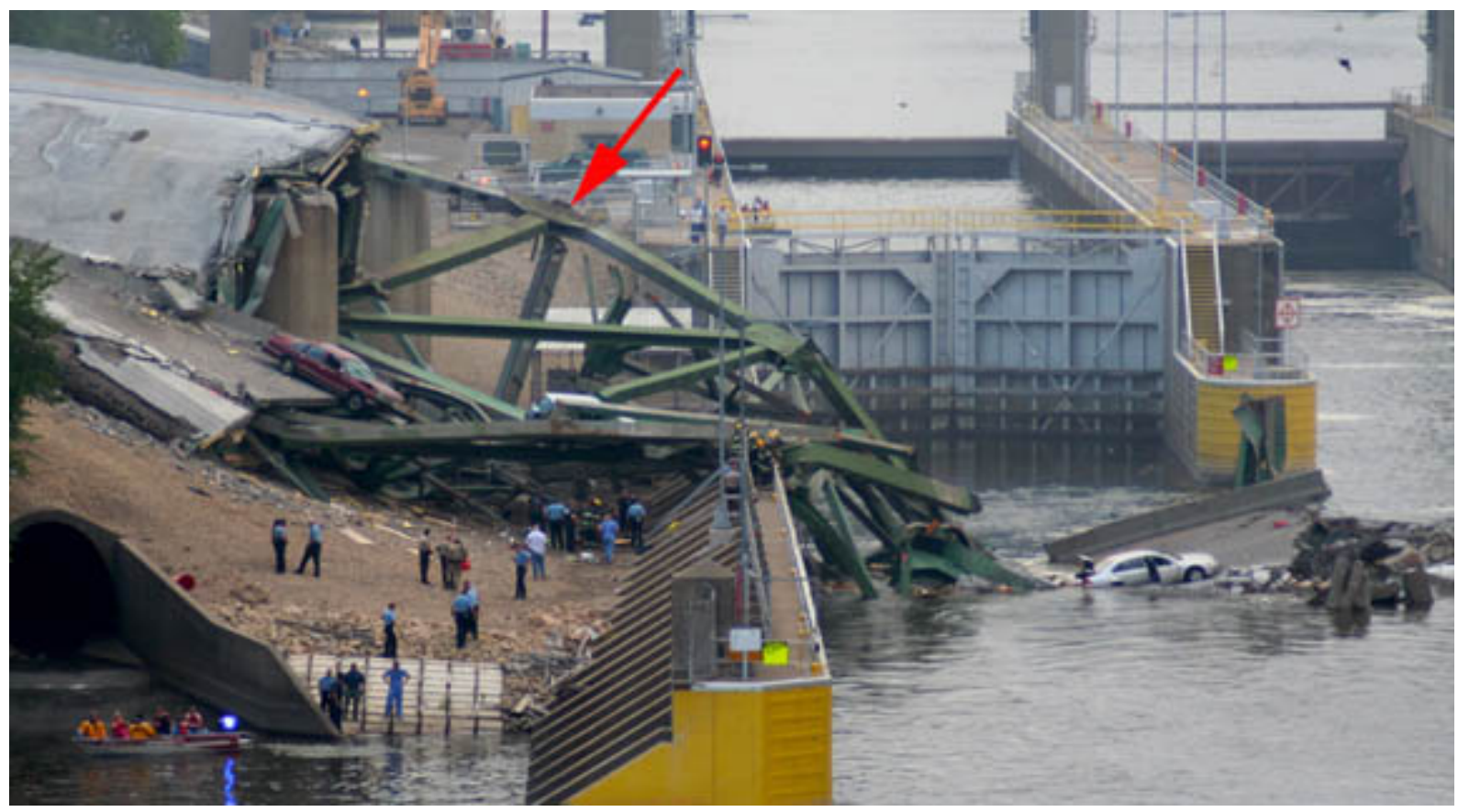

Figure 1. I35 bridge, Minneapolis bridge collapse (2007) 


\section{Bridge Detrimental Factors}

\subsection{Fatigue and Fracture}

Monotonically application of static loads in structural component may produce fracture and fail if the same load or even smaller is applied cyclically at a large number of times. For example a thin plate bent back and forth beyond yielding fails after a few cycles of such repeated bending: this is termed as the 'fatigue failure'. Examples of structures prone to fatigue failure, are bridges, cranes, offshore structures and slender towers, etc., which are subjected to cyclic loading. The fatigue failure is due to progressive propagation of flaws in steel under cyclic loading. This is partially enhanced by the stress concentration at the tip of such flaw or crack, as also recent collapse have evidenced (Figure 1). The presence of a hole in a plate or simply the presence of a notch in the plate creates stress concentrations. The stress at these points could be three or more times the average applied stress. These stress concentrations may occur in the material due to some discontinuities in the material itself and are not serious when a ductile material like steel is subjected to a static load, as the stresses redistribute themselves to other adjacent elements within the structure. At the time of static failure, the average stress across the entire cross section would be the yield stress; however when the load is repeatedly applied or the load fluctuates between tension and compression, the hot spot points experience a higher range of stress reversal than the applied average stress. These fluctuations involving higher stress ranges, cause minute cracks at these points, which open up progressively and spread with each application of the cyclic load and ultimately lead to rupture. The fatigue failure occurs after four different stages, namely: crack initiation at points of stress concentration; crack growth; crack propagation; final rupture. Fatigue failure can be defined as the number of cycles and hence time taken to reach a pre-defined or a threshold failure criterion. Fatigue failures are classified into two categories namely the high cycle and low cycle fatigue failures, depending upon the number of cycles necessary to create rupture. Low cycle fatigue could be classified as the failures occurring in few cycles to a few tens of thousands of cycles, normally under high stress/ strain ranges. High cycle fatigue requires about several millions of cycles to initiate a failure. However this distinction is not strictly defined. The common form of presentation of fatigue data is by using the S-N curve, where the total cyclic stress (S) is plotted against the number of cycles to failure $(\mathrm{N})$ in logarithmic scale. Typical S-N curve are shown in codes and standards. It could be seen that the fatigue life reduces with respect to increase in stress range and at a limiting value of stress, the curve flattens off. The point at which the S-N curve flattens off is commonly called the 'endurance limit'. To carry out fatigue life predictions, a linear fatigue damage model is used in conjunction with the relevant S-N curve. One such fatigue damage model is that postulated by Wohler. It becomes very important to avoid any local structural discontinuities and notches by good design and this is the most effective means of increasing fatigue life.

\subsubsection{Literature Review}

The fatigue argument is more related to bridge specialists, increasingly in the last years, as weight control in new bridges is becoming of importance to reduce the use of material, and to accelerate bridge construction. The Modelling and fatigue life assessment of orthotropic bridge deck details using FEM is deepen in Mustafa et al. (2012); while, the integrating reliability and structural health monitoring in the fatigue assessment of concrete bridge decks is studied in Newhook and Edalatmanesh (2013); the Fatigue assessment of a composite railway bridge for high speed trains is reported in Liu (2013) for the analysis of conditions for which a dynamic analysis is needed, while in Zhou et al. (2013) it could be found the modeling and fatigue critical details; if considering at the same time the monitoring option, the fatigue reliability assessment for bridge welded details using long-term monitoring data (by Deng Yang et al., 2011) is very useful; while the fatigue assessment of orthotropic steel bridge deck based on hot spot stress method by Qianhui et al. (2013) is of interest; a general approach to consider the Fatigue assessment and strengthening measures to upgrade a steel railway bridge is in Stamatopoulos (2013); while, the evaluation of fatigue strength of one riveted historical railway bridge (Pipinato et al., 2008b) is of interest for historical construction, as the high-cycle fatigue behavior of riveted connections for railway metal bridges (Pipinato et al., 2009, 2011c, 2014) where also full scale investigations are reported; the bridge fatigue reliability assessment using probability density functions of equivalent stress range based on field monitoring data (Kwon \& Frangopol, 2010) is a very useful study for expert of the matter; while for a more mechanical engineering based study, the crack water interaction and fatigue life assessment of reinforced concrete bridge decks is of interest (Maekawa \& Fujiyama, 2013), as the fracture mechanics approach as an improvement of fatigue life assessment in orthotropic bridge decks, by Nagy et al. (2013), or the fatigue damage assessment of steel bridge members using paint cracking (Okumura et al., 2010); a specific view on the fatigue damage estimation in existing railway steel bridges by detailed loading history analysis could be of interest for railway engineers (Pipinato et al., 2012e), and alsoconsidering fatigue/corrosion issues (Pipinato, 2012a, b), or 
FRP strengthening (Pipinato et al., 2012d); the Fatigue reliability assessment of steel bridge details integrating weigh-in-motion data and probabilistic finite element analysis is described in Guo (2012), while the fatigue crack assessment of asphalt concrete pavement on a single span highway bridge subjected to a moving truck is introduced in Youngguk et al. (2012), and the Bridge fatigue reliability assessment using probability density functions of equivalent stress range based on field monitoring data in Kwon and Frangopol (2010). Concerning new constructions, the influence of fatigue on cable arrangement in cable-stayed bridges could be finally found in Pipinato et al. (2012b), or as the structural analysis of the cantilever construction process in cable-stayed bridges found in Pipinato et al. (2012c); and if the moving load and fatigue analysis of a long span high speed railway bridge or the moving loads bridge response, considering the structural analysis and eurocode provisions are investigated, a good reference should be found in Pipinato (2013b, c).

\subsection{Seismic Issues}

As observed by Albon (1988) "bridges should be designed to absorb seismic forces without collapse to ensure that main arterial routes remain open after major seismic events. This helps the movement of aid and rescue services in the first instance and underpins the ability of the local community to recover in the long term". The following are the primary causes of the bridge seismic damage:

a) effects of site conditions: the significant impact that local site conditions have on amplifying strong ground motion, and the subsequent increased vulnerability of bridges on soft soil sites; furthermore, in some specific sites sites liquefaction and lateral spreading could enable permanent substructure deformations and loss of superstructure support;

b) correlation of damage with construction era: an excellent example of the effect of construction era is provided by observing the relative performances of bridges on Routes 3 (built in 1965) and 5 (built in 1990) of the Hanshin Expressway in Kobe, as in the first damages were catastrofics, while in the latter only concentrated damage were found; this is principally related to the new design method and awareness of the potential damage of eartquakes on infrastructures in critical zones; moreover, the use of benchmark years as a crude but effective method for rapidly assessing the likely performance of bridge construction;

c) design or construction changes: both changes are potentially very dangerous, as they could greatly affect its seismic performance; the first being a cause coming for the deterioration of the structure during the service life, while the latter due to construction modifications, not checked for the earthquake design requirements;

d) irregularities of the bridge: excessive deformation demands occuring in a few brittle elements, or the complex structural configuration, or a bridge lacks of redundancy could negatively influence the structural performance of a bridge during the seismic event;

e) unseating: expansion joints introduce a structural irregularity that can have catastrophic consequences;

f) special situations: these occurs for specific structures, as for skewed bridges (in which a rotation of the deck about a vertical axis could led to the collapse of the superstructure), curved bridges (for the asymmetrical response similar to that of skewed bridges);

g) superstructure: the most common form of damage to superstructures is due to pounding of adjacent segments at the expansion hinges; in particular, for steel girder, buckling of cross braces beneath the roadway could be found;

h) damage to bearings: in steel superstructures, the bearings commonly consist of steel components designed to provide restraint in one or more directions and, in some cases, to permit movement in one or more directions; failure of these bearings in an earthquake can cause redistribution of internal forces, which may overload specific structural members;

i) damage to substructures: also in older bridges, columns tend to be weaker than the beam-diaphragmslab assembly to which they connect. Consequently, columns can be subjected to large inelastic demands during strong earthquakes; this is often the primary cause of the whole structure collapse.

The risk associated to the seismic vulnerability of bridges and infrastructure in general is a relevant issue to guarantee standard safety and security of citizens in everyday life and moreover in the case of disaster. The example of this risk has been evidenced in Italy, where tragic events have kicked the nation also recently (Aquila, 2009; Emilia, 2012), and in the past -in the second half of the 20th century (Friuli, 1976; Irpinia, 1980)- even if the transportation infrastructure has not suffered significantly. In the Apennine mountains crossing of the A16 
highway the bridges did undergo some damage, mainly due to the inadequacy of the bearing devices, but this was promptly remedied by the owner through the systematic adoption of the seismic isolation. The delay in the appreciation of the risk is not exclusive to Italy, but also in US, the Federal Highway Administration (FHWA) published a first document titled "Retrofitting guidelines for Highway Bridges" some years after (FHWA-ATC, 1983) the San Fernando (1971) earthquake. Still, in 1989, despite of the large retrofit program developed, the Loma Prieta earthquake exposed substantial deficiencies in bridges in California (Pinto et al., 2011). Although, a relevant amount of bridges and viaduct, of medium and large span are present in the national infrastructural system (Figure, 1-2). The situation as briefly outlined above is sufficient to understand that the state of the art on seismic assessment and retrofit of bridges still needs to be advanced in several areas. The areas considered to be of priority interest were assessment methods, retrofit criteria and intervention techniques. Although, a relevant amount of work on existing bridge network has been performed in the past, a comprehensive overview of recent studies should help in the identification of the state of knowledge of the matter.

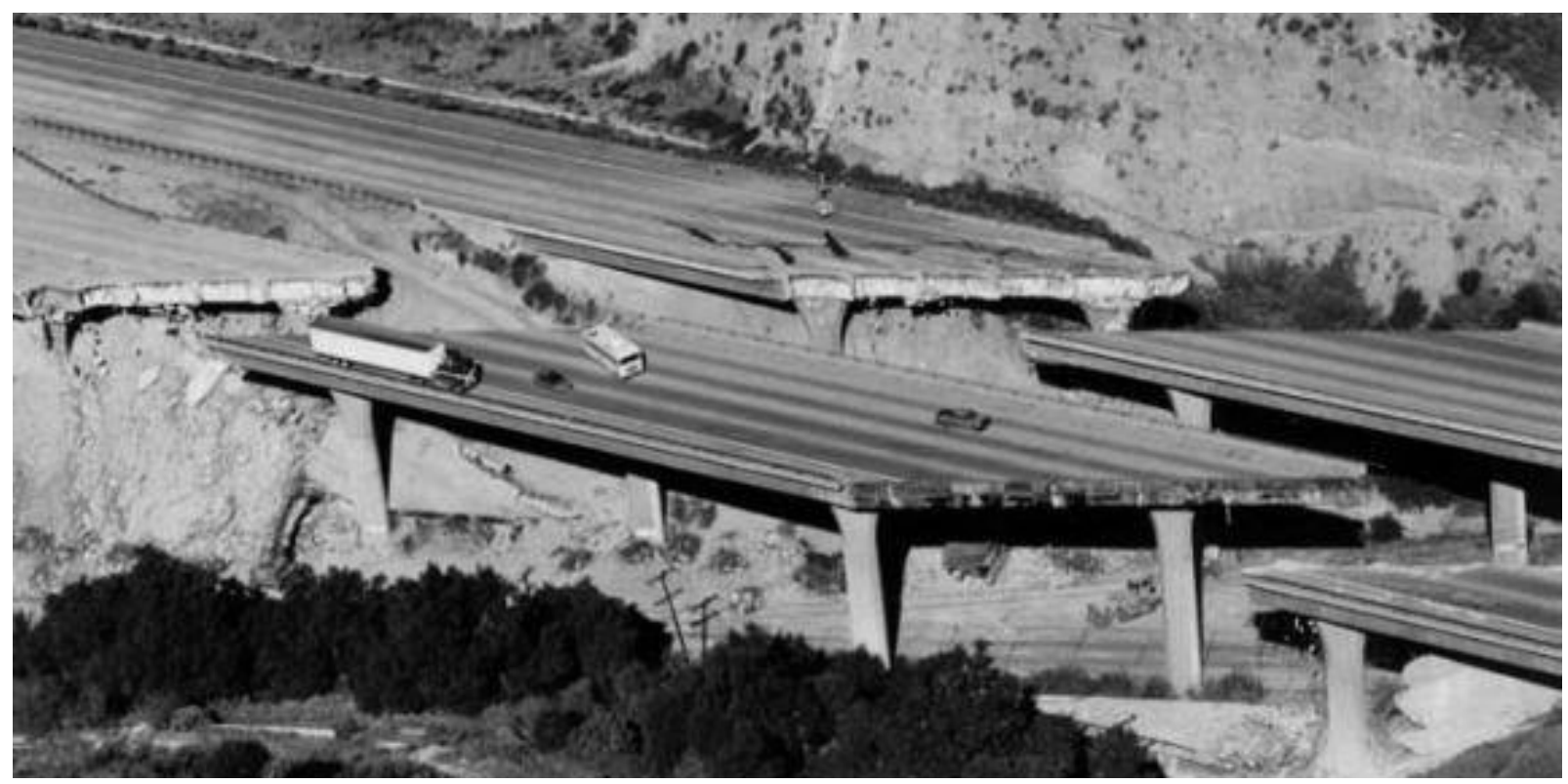

Figure 2. I5 bridge, Gavin Canion (1994)

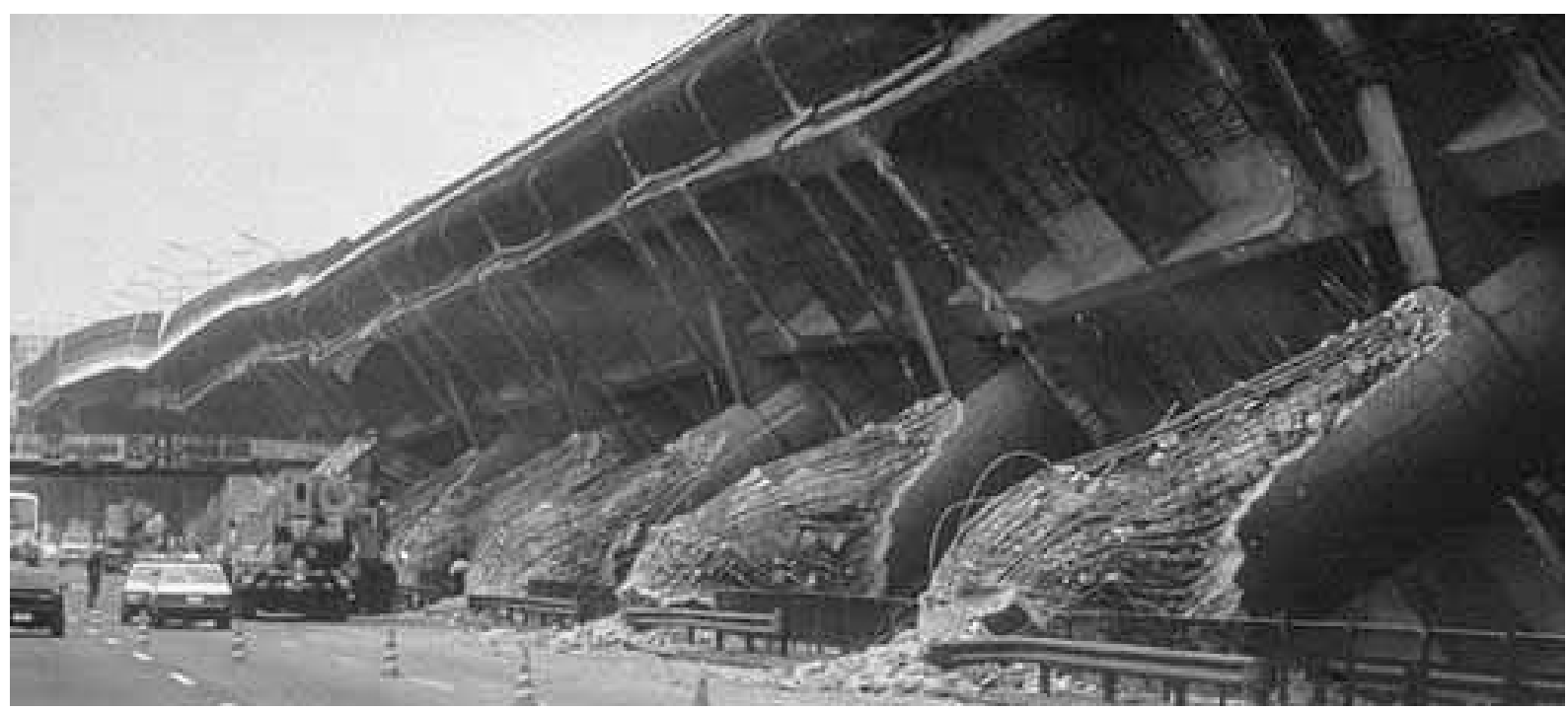

Figure 3. Hanshin Expressway elevated road, Japan (1995) 


\subsubsection{Literature Review}

The seismic hazard, and the inherent difficulties of upgrading existing bridges to current structural standards, is not a very interesting matter for the whole engineering world, as this specific problem is not relevant for all nations. However, the tragedy of the past, highlighted that research and studies are needed expecially in those countries where this is really a structural and safety problem (Figures 3 and 4). The literature is very rich of studies and research on the matter, as hidden nations have invested a wide amount of money to bridge the gap on not known seismic resistant solutions. The recent main relevant studies are enclosed in Aman et al. (2010) dealing with the seismic assessment of an existing non-seismically designed major bridge-abutment-foundation system, in (Nguyen et al., 2008) where a system modeling for seismic performance assessment and evaluation of reinforced concrete bridge columns is described, or in Taner and Caner (2012) where the target damage level assessment for seismic performance evaluation of two-column reinforced concrete bridge bents, or in Lau et al. (2012), where the fragility relationships for probabilistic performance-based seismic risk assessment of bridge inventories is explained, and finally in Ghosh and Padgett (2010) where the probabilistic seismic loss assessment of aging bridges using a component-level cost estimation approach is presented; specific applications for the seismic risk assessment for highway bridge system (by Chen et al., 2013), or concerning geotechnical probabilistic aspects (Bradley et al., 2010) and geotechnical applications (Thavaraj et al., 2012; Bayram et al., 2013) are useful for the completeness of the approach; if particular bridge geometrical shape are present, specific studies should be addressed: for e.g. curved bridges (Junwon \& Linzell, 2012), long span structures (Wen et al., 2013), hollow columns (Kim et al., 2012), cable stayed (Pipinato, 2012c), viaducts (Pipinato, 2011a, 2012b), existing bridges (Pipinato, 2012d), or bridge networks (Pipinato, 2013a). However, one of the most interesting chapter of this argument, deals with bridge isolation, as well illustrated in the Seismic assessment of bridge structures isolated by a shape memory alloy/rubber-based isolation system by Ozbulut and Hurlebaus (2011). According to the financial needs cited before, the study of the Performance-based Seismic Financial Risk Assessment for Bridge Structure by Zhang et al. (2011) is a reasonable approach to the matter. Other specific and relevant studies, involves for instance the Regional seismic risk assessment of bridge network (by Padgett et al., 2010), the nonlinear seismic assessment for the post-repair response of RC bridge piers by Do Hyung Lee et al. (2011), the analysis of seismic risk probability assessment of lower-tower cable-stayed bridge based on LHS-MC method (Yin et al., 2013), the performance Assessment of a Highway Bridge Structure Employing Adaptive Negative Stiffness for Seismic Protection (Attary et al., 2013), and inally as a comprehensive case study, the Probabilistic perforcemance-based seismic risk assessment of a bridge network should be cited (Waller \& Lau, 2010). The severe seismic hazard risk and recent events in Japan are related to a high level research and studies production: for e.g. in Zhang et al. (2013) the seismic damage of retrofitted highway bridges in the 2011 great east japan earthquake is described; Hisaya et al. (2012) describe the maintenance planning of deteriorating highway bridges with seismic risk; Iida et al. (2012) discussed the seismic performance evaluations of bridge-pier systems with uncertainty; Ge et al. (2012) presented a relevant study on the demand on stiffened steel shear panel dampers in a rigid-framed bridge pier under repeated seismic ground motions; Nogami et al. (2013) discussed on the seismic design of RC bridge piers to ensure the post-disaster functionality of road network.

\section{Conclusion}

In this study, a wide amount of very recent research have been reported on the general matter of bridge assessment, management and life cycle analysis. As existing bridges represents a strategic components of infrastructural nets, an accurate study of their remaining life basing on evidences is more often required. Matching with an increasing traffic flow, despite their increasing age, and even if subjected to an increasing heavy traffic, these nets stands generally in a good structural health, as prolonged out of service due to structural problems are rare. Nevertheless, it is important to highlight the major causes of degradation reported in bridges, so that to achieve an adequate maintenance and a design stage aware that new structures should ensure - during the lifetime - growing capacity and structural performance. At the same time it is crucial to understand how much work is undergoing in the specific matter of bridge assessment, a relatively recent bridge engineering science that is growing faster, because the whole amount of resources needed for the complete repair of existing bridges is absolutely impossibile to be retrieved for the owner or managing public authorities. Bridge assessment is in this case a scientific based and technical procedure, mainly not coded, aiming at producing evidences on the bridge health, of the structural reliability, and of the suggested procedure to prolong its life. According to this framework, this study, has provided a review of recent studies and research accomplishments in the field of bridge assessment, management and life cycle analysis, highlighting that there is a need to focus these studies on relevant problems. 


\section{References}

ANAS. (1997). Material and techniques of intervention for the restoration of the concretes of the bridges and viaducts (in Italian). Rome, Italy: Gangemi Ed.

ASCE. (2009). Report Card 2009 Grades. Asce web-site.

Attary, N., Symans, M., Nagarajaiah, S., Reinhorn, A. M., Constantinou, M. C., Taylor, D., \& Pasala, D. T. R. (2013). Performance Assessment of a Highway Bridge Structure Employing Adaptive Negative Stiffness for Seismic Protection. Proceedings of the Structures Congress 2013 (pp. 1736-46). http://dx.doi.org/10.1061/9780784412848.152

Aygül, M., Almrani, M., \& Urushadze, S. (2012). Modelling and fatigue life assessment of orthotropic bridge deck details using FEM. International Journal of Fatigue, 40, 129-142. http://dx.doi.org/10.1016/j.jfatigue.2011.12.015

Aygün, B., Dueas-Osorio, L., \& Padgett, J. E. (2011). Efficient longitudinal seismic fragility assessment of a multispan continuous steel bridge on liquefiable soils. Desroches, Reginald Source: Journal of Bridge Engineering, 16(1), 93-107. http://dx.doi.org/10.1061/(ASCE)BE.1943-5592.0000131

Bradley, B. A., Cubrinovski, M., Dhakal, R. P., \& MacRae, G. A. (2010). Probabilistic seismic performance and loss assessment of a bridge-foundation-soil system. Soil-Foundation-Structure Interaction - Selected Papers from the International Workshop on Soil-Foundation-Structure Interaction, SFSI 09 (pp. 221-228).

Bradley, B. A., Cubrinovski, M., Dhakal, R. P., \& MacRae, G. A. (2010). Probabilistic seismic performance and loss assessment of a bridge-foundation-soil system. Soil Dynamics and Earthquake Engineering, 30(5), 395-411. http://dx.doi.org/10.1016/j.soildyn.2009.12.012

Cakebread, T. (2010). The role of finite element analysis in bridge assessment and design. Bridge Maintenance, Safety, Management and Life-Cycle Optimization - Proceedings of the 5th International Conference on Bridge Maintenance, Safety and Management (pp. 2433-2439), 2010.

Chen, L., Zhang, J., \& Zhuo, W. (2013). Seismic risk assessment for highway bridge system in the Wenchuan region. Tumu Gongcheng Xuebao/China Civil Engineering Journal, 46(SUPPL. 2), 242-248.

Chen, X. Y., \& Fan, J. P. (2011). An improved one-dimensional optimization algorithm in non-probabilistic reliability investigation and its application in bridge assessment. Gongcheng Lixue/Engineering Mechanics, 28(5), 21-25, 30 .

Chunfeng W., Wan H., Jianxun L., Zhishen W., Zhaodong X., \& Shu L. (2013). Bridge Assessment and Health Monitoring with Distributed Long-Gauge FBG Sensors. International Journal of Distributed Sensor Networks, 494260, 2013.

Czepiel, E. (1995). Bridge management systems literature review and search. Technical report no. 11, Northwestern University BIRL Industrial Research Laboratory, Evanston, IN, USA.

Deng Y., Ding Y., Li A., \& Zhou G. D. (2011). Fatigue reliability assessment for bridge welded details using long-term monitoring data. Science in China Series E: Technological Sciences, 54(12), 3371-3381. http://dx.doi.org/10.1007/s11431-011-4526-6

Do, H. L., Joonam P., Kihak, L., \& Byeong, H. K. (2011). Nonlinear seismic assessment for the post-repair response of RC bridge piers. Composites Part B: Engineering, 42(5), 1318-1329. http://dx.doi.org/10.1016/j.compositesb.2010.12.023

Enright, B., Hajializadeh, D., \& Obrien, E. J. (2013). Reliability-based bridge assessment using enhanced Monte Carlo to simulate extreme traffic loading. Safety, Reliability, Risk and Life-Cycle Performance of Structures and Infrastructures - Proceedings of the 11th International Conference on Structural Safety and Reliability, ICOSSAR 2013 (pp. 3703-3708).

Figueiredo, E., Radu, L., Park, G., \& Farrar, C. (2011). Integration of SHM into bridge management systems: Case study-Z24 bridge. Structural Health Monitoring 2011: Condition-Based Maintenance and Intelligent Structures - Proceedings of the 8th International Workshop on Structural Health Monitoring, vol. 1, (pp. 725-732).

Gangone, M. V., Whelan, M. J., \& Janoyan, K. D. (2011). Deployment of a dense hybrid wireless sensing system for bridge assessment. Structure and Infrastructure Engineering, 7(5), 369-378. http://dx.doi.org/10.1080/15732470802670842 
Ghosh, J., \& Padgett, J. E. (2011). Probabilistic seismic loss assessment of aging bridges using a component-level cost estimation approach. Earthquake Engineering and Structural Dynamics, 40(15), 1743-1761. http://dx.doi.org/10.1002/eqe.1114

Griffin, M., \& Patro, S. (2013). Shaping Network Rail's bridge asset management. IET \& IAM Asset Management Conference 2013 (p. 104). http://dx.doi.org/10.1049/cp.2013.1924

Gu, Y., Zheng, W. T., \& Zhuo, W. D. (2013). Analysis of seismic risk probability assessment of lower-tower cable-stayed bridge based on LHS-MC method. Gongcheng Lixue/Engineering Mechanics, 30(8), 96-102.

Hisaya, F., Tanaka, S., Furuta, H., \& Dogaki, M. (2012). Maintenance planning of deteriorating highway bridges with seismic risk. Zairyo/Journal of the Society of Materials Science, Japan, 61(2), 133-140.

Iida T., Lim D., \& Kawano K. (2012). Seismic performance evaluations of bridge-pier systems with uncertainty. Bridge Maintenance, Safety, Management, Resilience and Sustainability - Proceedings of the Sixth International Conference on Bridge Maintenance, Safety and Management (pp. 2517-2524), Bridge Maintenance, Safety, Management, Resilience and Sustainability - Proceedings of the Sixth International Conference on Bridge Maintenance, Safety and Management.

Icke, P., \& Margheriti, C. (2012). The benefits and use of FE modelling in bridge assessment and design. Bridge Maintenance, Safety, Management, Resilience and Sustainability - Proceedings of the Sixth International Conference on Bridge Maintenance, Safety and Management (pp. 3191-3197).

Jin, Q. W., Wang, T. N., Sun, Y. L., \& Hu, Z. T. (2013). Seismic performance assessment of long span continuous rigid bridge. Applied Mechanics and Materials, 353, 2033-2038. http://dx.doi.org/10.4028/www.scientific.net/AMM.353-356.2033

Kihyon, K., \& Frangopol, D. M. (2010). Bridge fatigue reliability assessment using probability density functions of equivalent stress range based on field monitoring data. International Journal of Fatigue, 32(8), 1221-32. http://dx.doi.org/10.1016/j.ijfatigue.2010.01.002

Kim, T. H., Seong, D. J., \& Shin, H. M. (2012). Seismic Performance Assessment of Hollow Reinforced Concrete and Prestressed Concrete Bridge Columns. International Journal of Concrete Structures and Materials, 6(3), 165-176. http://dx.doi.org/10.1007/s40069-012-0015-y

Kwon, K., \& Frangopol, Dan M. (2010). Bridge fatigue reliability assessment using probability density functions of equivalent stress range based on field monitoring data. International Journal of Fatigue, 32(8), 1221-1232. http://dx.doi.org/10.1016/j.ijfatigue.2010.01.002

Lau, D. T., Waller, C. L., Vishnukanthan, K., \& Sivathayalan, S. (2012). Fragility relationships for probabilistic performance-based seismic risk assessment of bridge inventories. Proceedings, Annual Conference Canadian Society for Civil Engineering (vol. 4, pp. 2765-2774) 2012, Annual Conference of the Canadian Society for Civil Engineering 2012: Leadership in Sustainable Infrastructure, CSCE 2012.

Li, X. F., Ding, S. C., \& Wang, X. M. (2013). Methods for determining differences of attribute weight between evidences in bridge assessment. Advanced Materials Research, 760, 2172-2176. http://dx.doi.org/10.4028/www.scientific.net/AMR.760-762.2172

Liao, Y., Zhou, Y., \& Qin, P. (2013). Multiple reference impact testing for bridge assessment with drop hammer. Source: Advanced Materials Research, 605, 718-772.

Linya T., Xiaotao Y., \& Hui Z. (2010). Deformation predication and management of large bridge based on radial basis function neural network. 2010 International Conference on Management and Service Science (MASS 2010) (p. 4).

Liu, K., Zhou, H., Shi, G., Wang, Y. Q., Shi, Y. J., \& De Roeck, G. (2013). Fatigue assessment of a composite railway bridge for high speed trains. Part II: conditions for which a dynamic analysis is needed. Journal of Constructional Steel Research, 82, 246-254. http://dx.doi.org/10.1016/j.jcsr.2012.11.014

Maekawa, K., \& Fujiyama, C. (2013). Crack Water Interaction and Fatigue Life Assessment of RC Bridge Decks. Poromechanics V. Proceedings of the Fifth Biot Conference on Poromechanics (pp. 2280-9). http://dx.doi.org/10.1061/9780784412992.267

Marzouk, M. M., \& Hisham, M. (2011). Bridge information modeling in sustainable bridge management. ICSDC 2011: Integrating Sustainability Practices in the Construction Industry - Proceedings of the International Conference on Sustainable Design and Construction 2011 (pp. 457-466).

Morcous, G., Lounis, Z., \& Cho, Y. (2010). An integrated system for bridge management using probabilistic and 
mechanistic deterioration models: Application to bridge decks. KSCE Journal of Civil Engineering, 14(4), 527-537. http://dx.doi.org/10.1007/s12205-010-0527-4

Mwafy, A., Kwon, O., \& Elnashai, A. (2009). Seismic assessment of an existing non-seismically designed major bridge-abutment-foundation $\quad$ system. Engineering $\quad$ Structures, $\quad 32(8), \quad 2192-2209$. http://dx.doi.org/10.1016/j.engstruct.2010.03.022

Nagy, W., De Backer, H., \& Van Bogaert, Ph. (2013). Fracture mechanics as an improvement of fatigue life assessment in orthotropic bridge decks. Research and Applications in Structural Engineering, Mechanics and Computation - Proceedings of the 5th International Conference on Structural Engineering, Mechanics and Computation, SEMC 2013 (pp. 579-584).

Newhook, J. P., \& Edalatmanesh, R. (2013). Integrating reliability and structural health monitoring in the fatigue assessment of concrete bridge decks. Structure and Infrastructure Engineering, 9(7), 619-633. http://dx.doi.org/10.1080/15732479.2011.601745

Nguyen, T. L. T., Silva, P. F., Manzari, M. T., \& Belarbi, A. (2010). System modeling for seismic performance assessment and evaluation of reinforced concrete bridge columns. American Concrete Institute, ACI Special Publication, n 271 SP, p 125-146, 2010, Structural Concrete in Performance-Based Seismic Design of Bridges - Technical Session at the ACI Fall 2008 Convention.

Nogami, Y., Akiyama, M., \& Frangopol, D. M. (2013). Seismic design of RC bridge piers to ensure the post-disaster functionality of road network. Safety, Reliability, Risk and Life-Cycle Performance of Structures and Infrastructures - Proceedings of the 11th International Conference on Structural Safety and Reliability, ICOSSAR 2013 (pp. 3581-3586).

O’Brien, E. J., González, A., \& Znidaric, A. (2010). Recommendations for dynamic allowance in bridge assessment. Bridge Maintenance, Safety, Management and Life-Cycle Optimization - Proceedings of the 5th International Conference on Bridge Maintenance, Safety and Management (pp. 3434-3441).

Okumura, Y., Sakano, M., Horie, Y., \& Kobayasi, H. (2010). Fatigue damage assessment of steel bridge members using paint cracking. Bridge Maintenance, Safety, Management and Life-Cycle Optimization Proceedings of the 5th International Conference on Bridge Maintenance, Safety and Management (pp. 2103-2105).

Okumura, Y., Sakano, M., Horie, Y., \& Kobayasi, H. (2010). Fatigue damage assessment of steel bridge members using paint cracking. Bridge Maintenance, Safety, Management and Life-Cycle Optimization Proceedings of the 5th International Conference on Bridge Maintenance, Safety and Management (pp. 2111-2113).

Orcesi, A. D., \& Frangopol, D. M. (2011). A stakeholder probability-based optimization approach for cost-effective bridge management under financial constraints. Engineering Structures, 33(5), 1439-1449.

Ozbulut, O. E., \& Hurlebaus, S. (2011). Seismic assessment of bridge structures isolated by a shape memory alloy/rubber-based isolation system. Smart Materials and Structures, 20(1).

Padgett, J. E., Desroches, R., \& Nilsson, E. (2010). Regional seismic risk assessment of bridge network in Charleston, South Carolina. Journal of Earthquake Engineering, 14(6), 918-933.

Pellegrino, C., Pipinato, A., \& Modena, C. (2011b). A simplified management procedure for bridge network maintenance. Structure and Infrastructure Engineering, $341-351$. http://dx.doi.org/10.1080/15732470802659084

Petschacher, M. (2011). Use of b-wim data for bridge assessment. Applications of Statistics and Probability in Civil Engineering-Proceedings of the 11th International Conference on Applications of Statistics and Probability in Civil Engineering (pp. 2642-2648).

Pipinato, A. (2010a). Structural analysis and fatigue life assessment of the Paderno Arch Bridge. IABMAS 2010 - Bridge Maintenance, Safety, Management, Resilience and Sustainability - Proceedings of the Sixth International Conference on Bridge Maintenance, Safety and Management (pp. 1003-1007). Philadelphia, USA, 11-15 July 2010.

Pipinato, A. (2012b). Life cycle assessment of existing steel bridges considering corrosion and fatigue coupled problems. IABMAS 2012 - Bridge Maintenance, Safety, Management, Resilience and Sustainability Proceedings of the Sixth International Conference on Bridge Maintenance, Safety and Management (pp. 1003-1007). Stresa, Lake Maggiore, Italy, 8-12 July 2012. ISBN: 9780415621243. 
Pipinato, A. (2012c). Coupled damage in assessing the lifetime of bridge and viaducts. Life-Cycle and Sustainability of Civil Infrastructure Systems - Proceedings of the 3rd International Symposium on Life-Cycle Civil Engineering, IALCCE 2012 (pp. 2292-2297). Vienna, Austria, October 3-6, 2012. ISBN 9780415621267.

Pipinato, A. (2012d). Assessment procedures and strengthening of an existing metal bridge. IABMAS 2012 Bridge Maintenance, Safety, Management, Resilience and Sustainability - Proceedings of the Sixth International Conference on Bridge Maintenance, Safety and Management (pp. 3651-3655). Stresa, Lake Maggiore, Italy, 8-12 July 2012. ISBN: 9780415621243.

Pipinato, A. (2014a). Orthotropic steel deck design to extend the lifetime of plate and box girder bridge and viaducts. IABMAS 2014 - Bridge Maintenance, Safety, Management, Resilience and Sustainability Proceedings of the Seventh International Conference on Bridge Maintenance, Safety and Management. Shangai, China, 7-11 July 2014 (in print).

Pipinato, A. (2014b). Longitudinal web stiffening in steel girders: fracture propagation and life cycle design. IABMAS 2014 - Bridge Maintenance, Safety, Management, Resilience and Sustainability - Proceedings of the Seventh International Conference on Bridge Maintenance, Safety and Management. Shangai, China, 7-11 July 2014 (in print).

Pipinato, A. (2014c). Steel bridges: codes, design specifications and construction issues. IABMAS 2014 - Bridge Maintenance, Safety, Management, Resilience and Sustainability - Proceedings of the Seventh International Conference on Bridge Maintenance, Safety and Management. Shangai, China, 7-11 July 2014 (in print).

Pipinato A. (2014d). Steel bridge coatings and corrosion protection. IABMAS 2014 - Bridge Maintenance, Safety, Management, Resilience and Sustainability - Proceedings of the Seventh International Conference on Bridge Maintenance, Safety and Management. Shangai, China, 7-11 July 2014 (in print).

Pipinato, A., Pellegrino, C., \& Modena, C. (2010b). Residual service life of existing railway bridges. IABMAS 2010 - Bridge Maintenance, Safety, Management, Resilience and Sustainability - Proceedings of the Sixth International Conference on Bridge Maintenance, Safety and Management (pp. 1003-1007). Philadelphia, USA, 11-15 July 2010. ISBN: 9780415877862.

Pipinato, A. (2010a). Step level procedure for remaining fatigue life evaluation of one railway bridge. Baltic Journal of Road and Bridge Engineering, 5(1), 28-37. http://dx.doi.org/10.3846/bjrbe.2010.04

Pipinato, A. (2011). Assessment of existing bridges: Safety and security issues [Problemi di sicurezza nelle valutazioni strutturali di ponti esistenti]. Ingegneria Ferroviaria, 66(4), 355-371.

Pipinato, A. (2012c). Coupled safety assessment of cable stay bridges. Modern Applied Science, 6(7), 64-78. http://dx.doi.org/10.5539/mas.v6n7p64

Pipinato, A. (2013a). Retrofit procedures of bridge networks against seismic actions in Italy. Durability of Bridge Structures Proceedings of the 7th New York City Bridge Conference (pp. 215-228), 26-27 August 2013. Edited by Khaled M. Mahmoud, CRC Press 2013 Print ISBN: 978-1-138-00112-1 eBook ISBN: 978-1-315-85684-1.

Pipinato, A. (2013b). Moving load and fatigue analysis of a long span high speed railway bridge. Advanced Materials Research, 629, 403-408.

Pipinato, A. (2013c). Moving loads bridge response: Structural analysis and eurocode provisions. Advanced Materials Research, 629, 409-417.

Pipinato, A., \& Modena, C. (2010). Structural analysis and fatigue reliability assessment of the Paderno bridge. Practice Periodical on Structural Design and Construction, 15(2), 109-124. http://dx.doi.org/10.1061/(ASCE)SC.1943-5576.0000037

Pipinato, A., Molinari, M., Pellegrino, C., Bursi, O. S., \& Modena, C. (2011c). Fatigue tests on riveted steel elements taken from a railway bridge. Structure and Infrastructure Engineering, 7(12), 907-920. http://dx.doi.org/10.1080/15732470903099776

Pipinato, A., Pellegrino, C., \& Modena, C. (2008). Scheduled maintenance actions and residual life evaluation of railway infrastructures for metallic structure bridges [Interventi di manutenzione programmata e valutazione della vita residua delle infrastrutture ferroviarie da ponte a struttura metallica]. Ingegneria Ferroviaria, 63(2), 125-134.

Pipinato, A., Pellegrino, C., \& Modena, C. (2008b). Evaluation of fatigue strength of one riveted historical 
railway bridge. Bridge Maintenance, Safety Management, Health Monitoring and Informatics IABMAS '08 Proceedings of the Fourth International IABMAS Conference, Seoul, Korea, July 13-17 2008. Edited by Hyun-Moo Koh and Dan M . Frangopol, Taylor \& Francis 2008, Print ISBN: 978-0-415-46844-2, eBook ISBN: 978-1-4398-2843-4.

Pipinato, A., Pellegrino, C., \& Modena, C. (2010a). Structural analysis of historical metal bridges in Italy. Advanced Materials Research, $\quad$ 525-530. http://dx.doi.org/10.4028/www.scientific.net/AMR.133-134.525

Pipinato, A., Pellegrino, C., \& Modena, C. (2011a). Fatigue assessment of highway steel bridges in presence of seismic loading. Engineering Structures, 33(1), 202-209. http://dx.doi.org/10.1016/j.engstruct.2010.10.008

Pipinato, A., Pellegrino, C., \& Modena, C. (2012a). Assessment procedure and rehabilitation criteria for the riveted railway Adige Bridge. Structure and Infrastructure Engineering, 8(8), 747-764. http://dx.doi.org/10.1080/15732479.2010.481674

Pipinato, A., Pellegrino, C., \& Modena, C. (2012c). Structural Analysis of the Cantilever Construction Process in Cable-Stayed Bridges. Periodica Polytechnica: Civil Engineering, 56(2), 141-166.

Pipinato, A., Pellegrino, C., \& Modena, C. (2012d). Fatigue behaviour of steel bridge joints strenghtened with FRP laminates. Modern Applied Science, 6(10), 1-15.

Pipinato, A., Pellegrino, C., \& Modena, C. (2014). Residual life of historic riveted steel bridges: an analytical approach. ICE-Bridge Engineering, UK Institution of Bridge Engineers. http://dx.doi.org/10.1680/bren.11.00014.

Pipinato, A., Pellegrino, C., \& Modena, C. (2012e). Fatigue Damage Estimation in Existing Railway Steel Bridges by Detailed Loading History Analysis. ISRN Civil Engineering, 2012, Article ID 231674. http://dx.doi.org/10.5402/2012/231674.

Pipinato, A., Pellegrino, C., Bursi, O. S., \& Modena, C. (2009). High-cycle fatigue behavior of riveted connections for railway metal bridges. Journal of Constructional Steel Research, 65(12), $2167-2175$. http://dx.doi.org/10.1061/(ASCE)SC.1943-5576.0000037

Pipinato, A., Pellegrino, C., Fregno, G., \& Modena, C. (2012b). Influence of fatigue on cable arrangement in cable-stayed bridges. International Journal of Steel Structures, 12(1), 107-123. http://dx.doi.org/10.1007/s13296-012-1010-5.

Pipinato, A. (2014). Assessment and rehabilitation of steel railway bridges using fi bre-reinforced polymer (FRP) composites. Rehabilitation of Metallic Civil Infrastructure using Fiber-reinforced Polymer (FRP) Composites, Edited by Vistasp M. Karbhari. Woodhead Publishing Series in Civil and Structural Engineering: Number 51.

Pu, Q., Gao, L., Liu, Z., \& Shi, Z. (2013). Fatigue assessment of orthotropic steel bridge deck based on hot spot stress method. Source: Xinan Jiaotong Daxue Xuebao/Journal of Southwest Jiaotong University, 48(3), 395-401.

Qiang B., Labi, S., Sinha, K. C., \& Thompson, P. D. (2013). Multiobjective Optimization for Project Selection in Network-Level Bridge Management Incorporating Decision-Maker's Preference Using the Concept of Holism. Journal of Bridge Engineering, 18(9), 879-89.

Robert, W., Marshall, A., Shepard, R., \& Aldayuz, J. (2003). The Pontis bridge management system: state-of-thepractice in implementation and development. Proceedings of 9th international bridge management conference (pp. 49-60). Transportation Research Board, Washington, DC, USA.

Rong, L. (2010). The analysis and design of urban bridge safety early-warning management system. 2010 IEEE International Conference on Industrial Engineering \& Engineering Management (IE\&EM 2010) (pp. 1786-90).

Seo, J., \& Linzell, D. G. (2012). Horizontally curved steel bridge seismic vulnerability assessment. Engineering Structures, 34, 21-32.

Sigurdardottir, D., Hubbell, D., Sousa Afonso, J. P., \& Glisic, B. (2011). Streicker bridge: Assessment of structural health condition through static and dynamic monitoring. SHMII-5 2011 - 5th International Conference on Structural Health Monitoring of Intelligent Infrastructure.

Soma M. (2006). Development and implementation of bridge management system in aomori prefectural government. Advances in Bridge Maintenance, Safety Management, and Life-Cycle Performance, 
Proceedings of the Third International Conference on Bridge Maintenance, Safety and Management (pp. 16-19). July 2006, Porto, Portugal - IABMAS '06.

Stamatopoulos, G.N. (2013). Fatigue assessment and strengthening measures to upgrade a steel railway bridge. Journal of Constructional Steel Research, 80, 346-54.

Sunley, W. (1995). Pontis: a bridge inspection. Illinois Department of Transportation, Illinois Municipal Review (pp. 13-15).

Teresa, R. A., Premavathi, N., \& Gunasekaran, U. (2012). Seismic performance assessment of an existing road bridge using standard pushover analysis. Applied Mechanics and Materials, 147, $278-282$.

Thavaraj, T., Sy, A., Hamersley, B., Woolford, D. (2012). Geotechnical aspects of the seismic safety assessment and retrofit of the Knight Street Bridge. Proceedings, Annual Conference - Canadian Society for Civil Engineering (vol. 1, pp. 607-616), 2012, Annual Conference of the Canadian Society for Civil Engineering 2012: Leadership in Sustainable Infrastructure, CSCE 2012.

Thompson, P., Sobanjo, J., \& Kerr, R. (2013). Modeling the risk of advanced deterioration in bridge management systems. Transportation Research Record, 2360, 52-59.

Tian, H. Y., \& Liu, Q. W. (2012). The life-cycle information management practice of Shanghai Yangtze River Tunnel and Bridge Project. Harmonising Rock Engineering and the Environment - Proceedings of the 12th ISRM International Congress on Rock Mechanics (pp. 2157-2162).

Tong G., Frangopol, D. M., \& Yuwen, C. (2012). Fatigue reliability assessment of steel bridge details integrating weigh-in-motion data and probabilistic finite element analysis. Computers \& Structures, 112, 245-57.

Walbridge, S., Fernando, D., \& Adey, B. T. (2012). Modelling inspection and fatigue retrofitting by post-weld treatment in bridge management systems. Bridge Maintenance, Safety, Management, Resilience and Sustainability - Proceedings of the Sixth International Conference on Bridge Maintenance, Safety and Management (pp. 3960-3967).

Waller, C. L., \& Lau, D. T. (2010). Probabilistic perforcemance-based seismic risk assessment of Canadian bridges - A pilot study. 9th US National and 10th Canadian Conference on Earthquake Engineering 2010, Including Papers from the $4^{\text {th }}$ International Tsunami Symposium, v 6, p 5003-5012, 2010, 9th US National and 10th Canadian Conference on Earthquake Engineering 2010, Including Papers from the 4th International Tsunami Symposium.

Wang, J., \& Melbourne, C. (2010). Mechanics of MEXE method for masonry arch bridge assessment. Proceedings of the Institution of Civil Engineers: Engineering and Computational Mechanics, 163(3), 187-202.

Xiaofang, W., Hongchun, Y., Dongqing, X., \& Ziyong, X. (2012). Developing of management information system of road and bridge infrastructure based on ArcGIS engine. 2012 Proceedings of 2nd International Conference on Remote Sensing, Environment and Transportation Engineering (RSETE 2012) (pp. 3-10).

Yilmaz, T., \& Caner, A. (2012). Target damage level assessment for seismic performance evaluation of two-column reinforced concrete bridge bents. Bridge Structures, 8(3-4), 135-146.

Yokoyama, K., Inaba, N., Honma, A., \& Ogata, N. (2006). Development of Bridge Management System for Expressway Bridges in Japan. Advances in Bridge Maintenance, Safety Management, and Life-Cycle Performance, Proceedings of the Third International Conference on Bridge Maintenance, Safety and Management, 16-19 July 2006, Porto, Portugal - IABMAS '06.

Youngguk, S., Cheolmin, B., \& Kim, Y. R. (2012). Fatigue crack assessment of asphalt concrete pavement on a single span highway bridge subjected to a moving truck. Journal of Testing and Evaluation, 40(6), JTE104200.

Zhang, K., Zhu, X., Ni, Y., \& Jiang, H. (2011). Performance-based Seismic Financial Risk Assessment for Bridge Structure. China Railway Science, 32(1), 68-74.

Zhou, H., Liu, K., Shi, G., Wang, Y. Q., Shi, Y. J., \& De Roeck, G. (2013). Fatigue assessment of a composite railway bridge for high speed trains. Part I: Modeling and fatigue critical details. Journal of Constructional Steel Research, 82, 234-45.

Znidaric, A., \& Lavric, I. (2010). Applications of B-WIM technology to bridge assessment. Bridge Maintenance, Safety, Management and Life-Cycle Optimization - Proceedings of the 5th International Conference on Bridge Maintenance, Safety and Management (pp. 1001-1008). 


\section{Copyrights}

Copyright for this article is retained by the author(s), with first publication rights granted to the journal.

This is an open-access article distributed under the terms and conditions of the Creative Commons Attribution license (http://creativecommons.org/licenses/by/3.0/). 